\title{
Quem está ficando para trás? Uma Década de Evasão nos Cursos Brasileiros de Graduação em Administração de Empresas e Ciências Contábeis
}

\begin{abstract}
Resumo
A evasão em Instituições de Ensino Superior (IES) públicas e privadas está associada com perdas sociais, acadêmicas e econômicas consideráveis. Essas perdas afetam toda a sociedade, já que os cidadãos pagam, direta ou indiretamente, pela sua própria educação e a dos seus familiares. O principal objetivo deste estudo foi analisar o comportamento de evasão dos estudantes matriculados nos cursos de graduação em Administração de Empresas e Ciências Contábeis em IES brasileiras entre 2001 e 2010. As taxas de evasão foram pesquisadas por tipo de IES e correlacionadas com o percentual de estudantes que concluíram os seus cursos dentro do prazo ideal. As hipóteses foram testadas com o teste ANOVA, e as variáveis foram submetidas à análise de correspondência simples e múltipla. As estatísticas descritivas mostraram níveis mais altos de evasão nos cursos de Administração de Empresas do que em Ciências Contábeis, porém em níveis gerais mais baixos quando comparados com a literatura. $\mathrm{O}$ índice de prazo ideal de conclusão do curso foi maior para Ciências Contábeis, embora não significativamente. Menos de um quarto dos estudantes concluíram os seus cursos dentro do período esperado de cinco anos. Em geral, as conclusões indicam que os cursos de Ciências Contábeis têm taxas menores de evasão nas universidades e nos centros universitários, enquanto os cursos de Administração de Empresas têm taxas maiores de evasão nas faculdades, escolas, institutos e centros de ensino tecnológico. Os resultados deste estudo não pretendem ser uma generalização, mas representam padrões observados dentro das classificações adotadas no estudo.
\end{abstract}

Palavras chaves: Evasão. Ensino Superior Brasileiro, Cursos de Ciências Contábeis e Administração de Empresas.

\author{
Jacqueline Veneroso \\ Alves da Cunha \\ Doutora em Ciências Contábeis pela \\ Universidade de São Paulo e Professora \\ Adjunta na Universidade Federal de Minas \\ Gerais (UFMG). Contato: Av. Antonio Carlos \\ 6627, Face Sala 2039. Bairro: Pampulha. \\ Belo Horizonte-MG. CEP.: 31270-901. \\ E-mail: jvac@face.ufmg.br
}

\begin{abstract}
Márcia Martins Mendes De Luca Doutora em Contabilidade pela Universidade de São Paulo e Professora Associada na Universidade Federal do Ceará (UFC). Contato: Av. da Universidade, 2431. Bairro Benfica. Fortaleza-CE. CEP.: 60.020-180. E-mail: marciadeluca@ufc.br

\section{Gerlando Augusto Sampaio Franco de Lima Livre Docente em Contabilidade na Universidade de São Paulo e Professor Associado na Universidade de São Paulo (USP). Contato: Av. Prof. Luciano Gualberto, 908, FEA-3. Bairro: Cidade Universitária. São Paulo-SP. CEP.: 05508-010. \\ E-mail: gerlando@usp.br}

Edgard Bruno Cornacchione Jr. Livre Docente em Contabilidade na Universidade de São Paulo e Professor Titular na Universidade de São Paulo (USP). Contato: Av. Prof. Luciano Gualberto, 908, FEA-3. Bairro: Cidade Universitária. São Paulo-SP. CEP.: 05508-010.

E-mail: edgardbc@usp.br

\section{Ernani Ott}

Doutor em Ciências Contábeis pela Universidade de Deusto, Espanha e Professor titular da Universidade do Vale do Rio dos Sinos - UNISINOS. Contato: Av. Unisinos, 95. Bairro: Cristo Rei. São Leopoldo-RS. CEP.: 60.020-180.

E-mail: ernani@unisinos.br 


\section{Introdução}

O ingresso no ensino superior é visto por muitos como um dos rituais de passagem mais importantes na vida acadêmica do indivíduo. A pesquisa sobre o processo universitário revela a diversidade de situações e desafios enfrentados por estudantes durante a sua educação, alguns dos quais bem-sucedidos e recompensadores dos seus compromissos e esforços, outros resultando em insatisfação, desapontamento e frustração. Esta última pode levar à tristeza, baixo desempenho acadêmico, fracasso e, caso persistente, à evasão (Mercuri, Ajub, \& Bariani, 1998). Taxas crescentes de fracasso e evasão no ensino superior são provas da falta de sucesso das IES ao responder a estas situações.

Como mostrado por Silva Filho, Motejunas, Hipólito e Lobo (2007), a evasão estudantil é um problema mundial comum nas Instituições de Ensino Superior (IESs) associado a perdas consideráveis para os sistemas de ensino. A evasão pode ser definida como uma interrupção permanente do ciclo de estudo, impedindo que o estudante conclua o curso e obtenha um diploma, como consequência do fracasso tanto por parte do estudante como da instituição (Gaioso, 2005). Troelsen e Laursen (2014) estudaram o fenômeno, comparando as universidades dinamarquesas com outras instituições europeias e descobriram que o risco da evasão está, primordialmente, influenciado pela consecução e situação socioeconômica dos países. Para compensar tais circunstâncias pessoais desfavoráveis, as políticas dinamarquesas para o ensino superior incluem um sistema eficiente de doação e empréstimo (Troelsen \& Laursen, 2014).

A evasão, tanto nas instituições públicas como privadas, é sinônimo de perdas sociais, acadêmicas e econômicas. Estas perdas afetam a toda a sociedade, já que os cidadãos pagam, direta ou indiretamente, pela sua própria educação ou pela dos seus familiares. . A evasão afeta não somente os estudantes universitários que fracassam em obter um diploma, mas também todo o sistema de ensino e educadores que fracassam no cumprimento da sua missão, a sociedade (devido às perdas sociais e econômicas), além das famílias dos estudantes cujos projetos de longo prazo são frustrados.

A Secretaria de Educação Superior brasileira (SESu) estima que o custo da evasão nas IES federais esteja próximo a 486 milhões de reais por ano, enquanto que as IES privadas perdem, aproximadamente, $10 \%$ das suas receitas (Pereira, 2003). Pode-se argumentar que a evasão universitária preencha vagas que poderiam ter gerado um retorno melhor ao investimento se concedidas a outros pretendentes. Além disso, quando a evasão é o resultado de desempenho acadêmico fraco, a autoestima do estudante é impactada seriamente (Silva Filho et al., 2007; Yepes, Beltrán, Arrubla, Marín, Martínez, Tobón, \& Hoyos, 2007; Carmo, \& Polydoro, 2010).

As taxas de evasão universitária variam de acordo com a região, curso e tipo de instituição, mas, em geral, os números brasileiros não se diferenciam muito dos números dos bancos de dados internacionais. A taxa média anual em todas as IES brasileiras foi de $22 \%$ (públicas: $12 \%$ vs. privadas: $26 \%$ ) no período entre 2000 e 2005. Em um estudo realizado por Silva Filho et al. (2007), a taxa de evasão foi de, aproximadamente, 25\% no grupo compreendido por Ciências Sociais, Administração e Direito (a terceira maior entre os grupos analisados). Ao se compararem as taxas de evasão por região geográfica, a menor taxa (16\%) foi observada na região Norte do Brasil. As taxas anuais mais baixas e mais altas durante o período analisado foram encontradas na Medicina (4\%) e Computação (36\%) (Silva Filho et al., 2007). Os números dos países desenvolvidos não são substantivamente diferentes: na Suíça, a taxa de evasão era de 28,1\% em 2008, seis anos após a reforma de Bolonha (Wolter, Diem \& Messer, 2014), enquanto que na Alemanha a taxa subiu de 21\% para 25\% entre 2001 e 2008 (Heublein, 2014).

Apesar da expansão impressionante do ensino superior no Brasil, incluindo um aumento considerável no número de vagas, o acesso ao ensino universitário permanece bem limitado. Segundo a SESu, somente $11 \%$ dos brasileiros com idade ente 18 e 24 anos estão na universidade. No Chile, o percentual correspondente é de $24 \%$ (Brasil, 2003). Além disso, admissão na universidade, em si, não assegura um resultado bem-sucedido, em parte devido ao salto dramático do ensino secundário para o nível universitário com relação aos requisitos acadêmicos. 
Nos cursos de graduação em negócios, especialmente em Contabilidade e Administração de Empresas, a situação é semelhante. Ainda que nenhum estudo tenha sido encontrado focalizando especificamente as Ciências Contábeis e Administração, como mencionado acima, a área de Ciências Sociais, Negócios e Direito, das quais estes cursos são parte, estavam associadas com as taxas mais altas de evasão no trabalho de Silva Filho et al. (2007).

Muitos estudantes de Ciências Contábeis e Administração precisam trabalhar para a sua própria manutenção. De acordo com o Instituto Nacional de Estudos e Pesquisas Educacionais Anísio Teixeira (Inep), aproximadamente 40\% dos pretendentes que participam do Exame Nacional de Avaliação do Desempenho de Estudantes (Enade), com parte da sua inscrição nos cursos de Ciências Contábeis e Administração, têm alguma forma de emprego (Brasil, 2005). Manter um desempenho satisfatório tanto na escola como no emprego e conciliar horários conflitantes pode ser algo muito exigente e aumenta o risco de repetição de módulos, perdendo a motivação e, eventualmente, levando à evasão (Brasil, 1996 Souza, 1999; Hotza, 2000; Santos, \& Noronha, 2001; Biazus, 2004; Lins, \& Silva, 2005; Gaioso, 2005). Os estudantes podem também se tornar desestimulados pelo enorme contraste entre as suas expectativas no início da vida universitária e a realidade do ensino superior no Brasil.

A situação socioeconômica dos estudantes pode impactar, de maneira substantiva na escolha do curso universitário e da carreira. Alguns estudantes se inscrevem em cursos nos quais não estão especialmente interessados, mas que têm demanda baixa e, deste modo, as chances da admissão aumentam e permitem aos estudantes continuarem empregados. Isto significa, com frequência, fazer cursos noturnos, uma escolha associada com taxas mais altas de evasão na graduação e atraso na conclusão (Brasil, 1996; Souza, 1999; Veloso, \& Almeida, 2002; Pereira, 2004; Biazus, 2004; Lins, \& Silva, 2005; Gaioso, 2005).

Os aspectos relacionados ao prestígio da profissão deveriam, também, ser enfatizados. Segundo Rozenstraten (1992), carreiras tais como Engenharia, Direito e Medicina têm muito prestígio e geram expectativas de salários altos e status. Outras, como cursos de licenciaturas e bacharelado não têm o mesmo prestígio social, reduzindo a demanda por vagas e níveis salariais no mercado de trabalho. Diversos autores acreditam que estas últimas estão associadas às altas taxas de evasão (Brasil, 1996; Souza, 1999; Santos, \& Noronha, 2001; Veloso, \& Almeida, 2002; Gaioso, 2005).

Considerando-se que os cursos de Ciências Contábeis e Administração de Empresas apresentam muitas das características avaliadas em estudos nacionais e internacionais sobre evasão universitária, bem como a necessidade de se discutir a questão e encontrar maneiras para reduzir a taxa atual de evasão, o seguinte problema de pesquisa foi formulado: Qual é o perfil da evasão e do atraso na conclusão do curso dos estudantes brasileiros de Ciências Contábeis e Administração de Empresas?

Assim, o propósito geral deste estudo foi determinar o perfil da evasão e do atraso na conclusão do curso dos estudantes brasileiros de Ciências Contábeis e Administração de Empresas. As taxas de evasão foram determinadas de acordo com a forma da organização acadêmica (ou tipo de instituição acadêmica), e foi desenvolvido um índice para quantificar o percentual de estudantes que concluem os seus cursos dentro do prazo ideal. Esse indicador foi correlacionado à taxa de evasão.

Além das questões discutidas acima, este estudo é relevante para as questões relacionadas ao crescimento econômico e qualidade de vida. Nessa linha, vários pesquisadores demonstraram que o desenvolvimento e o retorno econômico dependem da eficiência do sistema de ensino, particularmente o ensino superior (Langoni, 1973; Reis, \& Barros, 1991; Fernandes, \& Menezes-Filho, 2000; Menezes-Filho, 2001; Fernandes, \& Narita, 2001; Cunha, 2007). 


\section{Plataforma Teórica}

As interrupções no processo educacional dos estudantes de graduação podem ser pesquisadas de diferentes formas e sob aspectos diferentes, mas todos devem considerar a relação entre o estudante e a IES, além das circunstâncias que levam à evasão ou à saída.

Enquanto alguns estudiosos focalizaram o processo de abandono dos cursos acadêmicos (Tinto, 1975; Bean, 1980; Astin, 1984), outros se preocuparam com o desenvolvimento de modelos analisando as características e as relações mútuas dos estudantes e das IES na busca de fatores de previsão da evasão (Pascarella, Duby \& Iverson, 1983; Cabrera, Castañeda, Nora, \& Hengstler, 1992; Chapman, \& Pascarella, 2005).

Ribeiro (1991) comparou as taxas da transição de série baseadas no censo escolar (repetição, aprovação e evasão) fornecidas pela Secretaria de Estatísticas do Ministério da Educação e Cultura (MEC) com as taxas obtidas por meio de um modelo matemático (Profluxo), utilizando os dados da Pesquisa Nacional por Amostra de Domicílios (PNAD) realizada pelo Instituto Brasileiro de Geografia e Estatística (IBGE). A comparação revelou que, ao contrário dos dados do MEC, as taxas de evasão escolar foram muito baixas no primeiro ano do ensino secundário. Segundo o autor, a noção comum de que as crianças brasileiras são motivadas pela ordem social ou cultural para a evasão escolar precoce não tem sustentação. $\mathrm{Na}$ realidade, as famílias fazem esforços significativos para manter os seus filhos na escola.

Cobrindo o período entre 1995 e 1999, Polydoro (2000) pesquisou a prática de trancar matrícula e a situação dos estudantes universitários em Campinas (São Paulo, Brasil) na saída e no retorno à escola. $\mathrm{O}$ autor constatou que um percentual pequeno de estudantes conseguiu retornar ao curso após o afastamento, trancamento da matrícula ou abandono.

Noronha, Carvalho e Santos (2001) observaram que somente 50\% dos estudantes admitidos no curso de Administração de Empresas da Escola de Economia, Administração de Empresas e Contabilidade da Universidade de São Paulo, em Ribeirão Preto, entre 1992 e 1995, se formaram, e que 12,5\% dos estudantes matriculados em 1992 ainda estavam matriculados em fevereiro de 2000, enquanto 35\% haviam abandonado. Assim, além das altas taxas de evasão, as IES brasileiras enfrentam também problemas de atraso na conclusão dos cursos.

Cobrindo o período entre 1984 e 1997, Leon e Menezes-Filho (2002) realizaram uma análise descritiva dos fatores que determinam o fracasso na aprovação e o fracasso relacionado à evasão estudantil na quarta e oitava séries do ensino fundamental e no terceiro ano do ensino médio no Brasil. Os autores avaliaram os determinantes da seleção dos indivíduos durante o período escolar, concentrando a análise nas características familiares e nos seus efeitos sobre as chances de sucesso. Os autores concluíram que esses efeitos são mais importantes nas séries mais avançadas e, principalmente, como determinantes do avanço escolar, e que as características familiares perderam parte de sua importância durante o período analisado, apontando para a universalização do ensino. Em um estudo envolvendo 456 estudantes matriculados no curso de Administração de Empresas em uma IES pública, Corrêa e Noronha (2004) avaliaram os comportamentos da evasão e observaram a tendência de adiar a conclusão do curso, uma prática associada ao aumento do risco de evasão. Entre os estudantes admitidos no período entre 1992 e 2002, 76 $(16,67 \%)$ abandonaram, enquanto 39 tendiam a abandonar (trancar matrícula e atrasar a conclusão), elevando potencialmente a taxa de evasão para $25,22 \%$. Os autores sugeriram a realização de mais pesquisas sobre as causas desse comportamento e pela busca de soluções alternativas.

Silva et al. (2007) estudaram o processo de evasão no ensino superior brasileiro entre 2000 e 2005 e encontraram taxas de evasão de 9 a $15 \%$ para as IES públicas e $26 \%$ para as IES privadas. A taxa média anual brasileira de evasão era de $22 \%$, comparada aos $25 \%$ na área das Ciências Sociais, Negócios e Direito. Nas áreas de Educação e Serviços, a taxa era de 18\% e de 29\%, respectivamente. Dos 47 cursos analisados no estudo, a Matemática apresentou a taxa média de evasão mais alta (30\%) e a Medicina a mais baixa (4\%). Segundo os autores, devido à heterogeneidade da amostra, as taxas de evasão observadas não podem ser comparadas diretamente às dos estudos internacionais. 
Palharini (2008) analisou o perfil da evasão dos estudantes de línguas e literatura na Universidade Federal Fluminense (Rio de Janeiro, Brasil) e concluiu que a decisão do estudante de abandonar os cursos era determinada não tanto pelo desempenho acadêmico fraco, mas por falta de vocação, problemas familiares e expectativas contraditórias em função do custo da vida universitária e a ausência de perspectiva relacionada ao mercado de trabalho.

Platt Neto, Cruz e Pfitscher (2008) trataram dos problemas e dos riscos de se utilizarem as taxas de evasão escolar como indicador nas avaliações de desempenho das IES públicas. Segundo os autores, a contribuição relativa dos fatores motivadores da evasão sobre os quais a instituição não tem controle precisa ser determinada antes de se proporem soluções.

Moraes e Theóphilo (2010) identificaram e analisaram os fatores associados com a evasão dos estudantes admitidos no curso de Ciências Contábeis na Universidade Estadual de Montes Claros (Minas Gerais, Brasil) entre 1993 e 2002. Os resultados mostraram que a maioria dos estudantes evadidos (63\%) estavam empregados enquanto cursavam a faculdade; $21 \%$ já tinham um diploma quando da admissão no curso; e a maioria havia se formado em escolas de ensino médio privadas. A razão principal para o abandono relatada pelos entrevistados foi a falta de vocação. Os autores concluíram que a evasão é um fenômeno relevante nos cursos de Ciências Contábeis e que, apesar dos seus efeitos negativos na sociedade, pouco havia sido feito para controlá-la. Segundo Cislaghi (2008), a evasão é um processo multidimensional que deveria ser interpretado à luz da interação entre o indivíduo, o ambiente institucional (professores, pares, instituição) e a realidade social (família, expectativas, mercado de trabalho, etc.).

Em geral, a pesquisa sobre a evasão universitária no Brasil deveria considerar os fatores sociais. Ao contrário dos estudantes da maioria dos países desenvolvidos, os estudantes brasileiros financiavam, com frequência, a sua própria educação universitária e precisavam conciliar o emprego e a escola. Não é surpreendente, portanto, que muitos escolhem se matricular nos cursos noturnos.

Em um estudo recente, Wolter et al. (2014, pp. 472-473) examinaram os tópicos recorrentes nos estudos sobre evasão e os tópicos que necessitavam de mais pesquisa. Os tópicos estão resumidos no Figura 1:

\begin{tabular}{|ll|}
\hline Gênero & $\begin{array}{l}\text { A vasta maioria dos estudos encontra um alto risco final de evasão para os estudantes homens, } \\
\text { mas nenhuma diferença de gênero clara com relação à probabilidade de se alterar o sujeito do } \\
\text { estudo. }\end{array}$ \\
\hline A maioria dos estudos reconhece uma conexão clara entre a idade em que se inicia a \\
universidade e o risco de evasão: quanto mais velho o estudante maior o risco. Entretanto, na \\
maioria dos estudos, a conexão não é linear. Uma distinção precisa ser feita entre a evasão, \\
isto é, deixar a universidade e abandonar o estudo de um curso específico para mudar para um \\
novo. Os estudantes mais jovens parecem ter maior probabilidade de mudar de curso. O efeito \\
da idade do estudante está associado com a observação que, segundo os resultados de alguns \\
estudos, o tempo entre obter o bacharelado e iniciar o estudo universitário tem um impacto \\
negativo sobre as chances de sucesso na universidade.
\end{tabular}




\begin{tabular}{|c|c|}
\hline $\begin{array}{l}\text { Desempenho } \\
\text { acadêmico }\end{array}$ & $\begin{array}{l}\text { Diversos estudos analisaram a influência da integração acadêmica sobre o risco de evasão. } \\
\text { Como esperado, a maioria encontrou um elo negativo entre as notas obtidas, o número de } \\
\text { provas realizadas e aprovadas, além de outros fatores objetivos e o risco de evasão. Efeitos } \\
\text { semelhantes também são encontrados na motivação para estudar e os esforços que os } \\
\text { estudantes devotam para estudar. Em outras palavras, não se pode esperar que os estudantes } \\
\text { abandonem aleatoriamente, mas aqueles cujo comportamento no estudo já mostra uma } \\
\text { integração fraca no processo acadêmico podem ter maior probabilidade de fazê-lo. }\end{array}$ \\
\hline Curso & $\begin{array}{l}\text { A maioria dos estudos encontrou pequenas diferenças entre o risco de evasão nos diferentes } \\
\text { cursos. O risco maior é primordialmente encontrado nas 'ciências duras' (em nosso contexto as } \\
\text { ciências exatas e naturais, medicina e farmácia, etc.). Contudo, não é possível uma opinião final } \\
\text { com base na literatura disponível porque, como regra, a composição da população estudantil } \\
\text { nos diferentes cursos e as condições do quadro institucional (estrutura de estudo, formas de } \\
\text { provas, razão funcionários/estudante etc.) podem diferir enormemente de acordo com o curso. }\end{array}$ \\
\hline $\begin{array}{l}\text { Recursos da } \\
\text { universidade }\end{array}$ & $\begin{array}{l}\text { Os parâmetros, tais como a razão funcionários/estudante e o gasto por estudante, quase que } \\
\text { somente foram analisados nos estudos em inglês. Eles mostram uma conexão positiva entre } \\
\text { os recursos e o sucesso no estudo, especialmente com relação à percepção subjetiva da razão } \\
\text { funcionários/estudante. }\end{array}$ \\
\hline
\end{tabular}

Figura 1. Tópicos relevantes nos estudos sobre evasão universitária

Fonte: Wolter et al. (2014, pp. 472-473).

Segundo Silva Filho et al. (2007), enquanto as instituições e os estudantes com frequência atribuem às dificuldades financeiras a razão principal para a evasão, estudos de campo mostraram que isto é uma simplificação da problemática: na realidade, com frequência os estudantes perdem o interesse devido às questões acadêmicas, desapontamento e dificuldades de se ajustar à instituição.

Além disso, o cenário social brasileiro atual impõe dificuldades aos estudantes, tornando a inclusão profissional mais difícil e reduzindo as possibilidades de sucesso para aqueles que tenham somente o diploma de graduação. De acordo com Soares (2002), isso produziu um sentimento geral de impotência entre os estudantes recém formados do ensino médio, escolas técnicas/profissionalizantes ou faculdade, que se sentem despreparados para o mundo do trabalho.

Assim, surge um cenário de instabilidade e incerteza sobre o futuro, com profissionais profundamente preocupados com a sua capacidade de assegurar um emprego capaz de lhes proporcionar estabilidade econômica e financeira (Teixeira, 2002; Bardagi, Lassance, Paradiso \& Menezes, 2006; Bardagi, 2007). Essa preocupação chega aos estudantes matriculados atualmente, a até mesmo para aqueles que se encontram no processo de escolher a sua profissão, motivando-lhes a escolher cursos baseados nas expectativas de grandes ganhos financeiros, poder e prestígio social (Bardagi, 2007) em vez da vocação.

Essa situação conflita com as expectativas dos estudantes de realização pessoal por meio de uma profissão compatível com a sua vocação. A falta de conhecimento dos estudantes sobre a profissão, o respectivo processo educacional e as suas próprias aptidões frequentemente levam à frustração durante o curso, quando há pouca ou nenhuma convergência entre as suas aptidões e as competências exigidas no processo de aprendizado (Nassar, Ohira, Cislaghi, \& Rodrigues, 2008).

A pesquisa sobre a evasão universitária é relevante socialmente devido aos inúmeros recursos financeiros desperdiçados quando um estudante desiste de uma vaga a em uma IES, enquantooutro, potencialmente qualificado, é privado de uma oportunidade. Juntos, o grande número de evasões e o número de vagas que permanecem vazias, devido às matriculas baixadas, revelam um cenário de perdas sociais em escala, com muitas oportunidades não sendo aproveitadas e de perdas consideráveis de recursos públicos e privados todos os anos. 


\section{Metodologia}

Em vista dos objetivos da pesquisa, este estudo pode ser considerado descritivo, em que as características de uma certa população ou fenômeno foram analisadas e descritas e as associações entre as variáveis do estudo foram avaliadas (Sampieri, Collado, \& Lucio, 2006). A abordagem metodológica foi teórico-empírica com relação às limitações dos critérios de cientificidade e a coleta de evidências que permitem avançar no campo do estudo e fazer inferências à luz do quadro teórico (Gall, Gall, \& Borg, 2003; Martins, \& Theóphilo, 2009).

Foi empregado um conjunto de técnicas para coletar, registrar, compilar e analisar os dados para a interpretação quantitativa. A abordagem quantitativa tornou possível avaliar o processo de evasão, enquanto que a revisão da literatura forneceu os fundamentos sobre os quais se pode contextualizar a interpretação das conclusões.

\subsection{Desenho do estudo}

Para satisfazer aos objetivos do estudo e determinar as taxas de evasão nos cursos de Ciências Contábeis e de Administração de Empresas, um banco de dados foi elaborado a partir dedados retirados dos relatórios do Inep (Sinopses do Ensino Superior), cobrindo o período entre 2001e 2010.

A amostra consistiu de IES brasileiras que ofereciam os cursos de Ciências Contábeis e de Administração de Empresas durante o período do estudo.

A informação recolhida foi organizada em tabelas e figuras para determinar a taxa anual de evasão de acordo com o modelo proposto por Silva Filho et al. (2007), verificar as relações e fazer comparações. Nesse modelo, o percentual de evasão para um dado ano (n) é calculado da forma que segue:

$$
E_{(n)}=1-\frac{M_{(n)}-I_{(n)}}{M_{(n-1)}-C_{(n-1)}}
$$

Onde,

$E=$ evasão

$M=$ número de estudantes matriculados

$C=$ número de formandos

$I=$ número de estudantes novos

$n=$ ano sob análise

$n-1=$ ano anterior

Após calcular a taxa de evasão de cada curso de Ciências Contábeis e de Administração de Empresas, as taxas foram calculadas para todo o grupo de IES e de acordo com a forma de organização acadêmica. A taxa de evasão foi então comparada com o índice do prazo ideal para conclusão do curso, derivado dos dados disponíveis, usando a fórmula seguinte:

$$
I T C C I=\frac{C_{t+5}}{M_{t}}
$$

Onde,

ITCCI = indice do prazo ideal para conclusão do curso

$M_{t}=$ número de estudantes matriculados no período $t$

$C_{t+5}=$ número de formandos no período $t+5$ 
Como premissa, um período de cinco anos foi considerado como prazo ideal para concluir qualquer dos dois cursos. Contrariamente, o índice de conclusão do curso após o prazo ideal corresponderia a 1-ITCCI.

As IES brasileiras estão classificadas em quatro tipos básicos de acordo com o Decreto Normativo $\mathrm{n}^{\circ} 40$ do MEC (editado em 12 de dezembro de 2007): a) Universidades: instituições multicurriculares de ensino superior para o exercício profissional, pesquisa, extensão e o progresso e divulgação do conhecimento; b) Centros Universitários: instituições multicurriculares de ensino superior caracterizadas pela excelência do ensino oferecido, a qualificação dos professores e disponibilidade de instalações para pesquisa; c) Faculdades: instituições de ensino superior credenciadas pelo MEC; eventualmente, algumas se transformam em universidades ou centros universitários desde que funcionem regularmente e com padrões de qualidade satisfatórios; e d) Escolas, Institutos e Centros de Ensino Tecnológicos: instituições com múltiplos campi de ensino superior, oferecendo ensino profissionalizante/comercial/tecnológico sob diferentes regimes de ensino, realizando pesquisa aplicada e apoiando o desenvolvimento de novas tecnologias, produtos e serviços.

Para o propósito deste estudo, as IES foram classificadas em três tipos de instituição: i) universidades, ii) centros universitários, e iii) faculdades, escolas, institutos e centros de ensino tecnológico.

\subsection{Hipóteses}

As discussões sobre o fenômeno da evasão nos cursos de graduação em Ciências Contábeis e Administração de Empresas nas IES brasileiras beneficiam diretamente o ensino ao fornecer subsídios acadêmicos para melhorias. Segundo Wolter et al. (2014), a pesquisa sobre a evasão abrange uma gama variada de tópicos que podem ser organizados sob os seguintes títulos: gênero, idade, antecedentes socioeconômicos, competências, procedimentos de admissão, desempenho, curso e recursos da universidade. Nesse sentido, o propósito deste estudo foi avaliar as taxas de evasão em duas áreas importantes das Ciências Sociais (Ciências Contábeis e Administração de Empresas), considerando as características de cada forma de organização institucional. Assim, baseado nas teorias expostas no referencial teórico e na literatura revisada, e considerando as características inerentes de cada curso e tipo de instituição acadêmica (ou forma de organização acadêmica), foram formuladas as hipóteses seguintes:

Hipótese 1: não existe diferença estatisticamente significativa entre as taxas de evasão nos cursos de Administração de Empresas e Ciências Contábeis;

Hipótese 2: não existe diferença estatisticamente significativa entre o índice do prazo ideal de conclusão do curso (ITCCI) nos cursos de Administração de Empresas e Ciências Contábeis;

Hipótese 3: existe diferença estatisticamente significativa entre as taxas de evasão nas diferentes formas de organização acadêmica analisadas;

Hipótese 4: não existe diferença estatisticamente significativa entre o índice do prazo ideal de conclusão do curso (ITCCI) nas diferentes formas de organização acadêmica analisadas.

Os dados coletados foram colocados numa planilha eletrônica (instrumento de coleta) e processados com o uso do programa SPSS (Statistical Package for Social Sciences). Foram calculadas as taxas de evasão e o ITCCI e os valores médios foram comparados para identificar diferenças possíveis entre as variáveis relacionadas aos cursos de graduação em Ciências Contábeis e Administração de Empresas. Os dados foram submetidos também a uma análise de correspondência simples e multivariada (HOMALS), com a variável do tempo incorporada à análise. 


\section{Análise}

Foram analisadas as evasões ocorridas nos cursos de Administração de Empresas e Ciências Contábeis oferecidos por IES brasileiras durante o período de 2001 a 2010. Os dados foram retirados dos relatórios do Inep (2012). Para homogeneizar certas divisões/caracterizações modificadas na série temporal, as instituições foram segregadas em três tipos: i) universidades; ii) centros universitários; e iii) faculdades, escolas, institutos e centros de ensino tecnológico.

As taxas de evasão e o ITCCI foram calculados usando as fórmulas apresentadas na Seção 3.1, a primeira das quais foi proposta por Silva Filho et al. (2007).

A estatística descritiva para os dados de evasão por cursos é apresentada na Tabela 1, após a exclusão de cinco valores atípicos (dois dos cursos de Administração de Empresas oferecidos por faculdades, institutos e centros de ensino tecnológico em 2001 e 2010; dois dos cursos de Administração de Empresas oferecidos por universidades em 2009 e 2010; e um de um curso de Ciências Contábeis oferecido por um centro universitário em 2004).

Tabela 1

Estatística descritiva das taxas de evasão por curso

\begin{tabular}{ccccc}
\hline \multicolumn{1}{c}{ Curso } & Média & Mediana & Desvio padrão & Coeficiente de Variação \\
\hline Administração & $16,24 \%$ & $14,58 \%$ & $7,69 \%$ & $47,35 \%$ \\
\hline Ciências Contábeis & $12,45 \%$ & $9,69 \%$ & $6,72 \%$ & $53,97 \%$ \\
\hline Fonte: os autores & & & &
\end{tabular}

Como mostrado na análise, a taxa de evasão média foi mais alta para os cursos de Administração de Empresas (16,24\%) do que para os cursos de Ciências Contábeis (12,45\%). Essas taxas são mais baixas do que as taxas relatadas por Silva et al. (2007) para a área de Ciências Sociais, Negócio e Direito, e as taxas relatadas por Noronha et al. (2001) e por Corrêa e Noronha (2004) para os cursos de Administração de Empresas. A mediana foi algo mais baixo do que a média (14,58\% vs. 16,24\% em Administração de Empresas, e 9,69\% vs. 12,45\% em Ciências Contábeis). O coeficiente de variação alto (>30\%) (i.e., a variação entre o desvio padrão e a média) revelou variação considerável ano a ano nos dados. A mediana indicou, também, que as taxas de evasão foram mais altas nos cursos de Administração de Empresas do que nos cursos de Ciências Contábeis. Para determinar se a diferença nas taxas de evasão era significativa, foram testadas as diferenças entre as médias. Após o teste de normalidade de Shapiro-Wilk (Administração de Empresas $p=0.569$; Ciências Contábeis $p=0.078$ ) e o teste de homocedasticidade das variáveis de Levene ( $p=0.678$ ), o teste $t$ de student para médias independentes foi considerado como sendo a melhor opção $(p=0.057)$. Assim, a Hipótese 1 ("não existe diferença estatisticamente significativa entre as taxas de evasão nos cursos de Administração de Empresas e Ciências Contábeis") não foi rejeitada. Em outras palavras, apesar da taxa de evasão média mais alta observada nos cursos de Administração de Empresas, a diferença não é estatisticamente significativa no nível de confiança de 95\%. Isso pode ocorrer porque os alunos matriculados nos dois cursos têm características semelhantes (a maioria empregada e/ou fazendo cursos noturnos). 
A Figura 2 mostra a taxa de evasão anual média de acordo com os cursos.

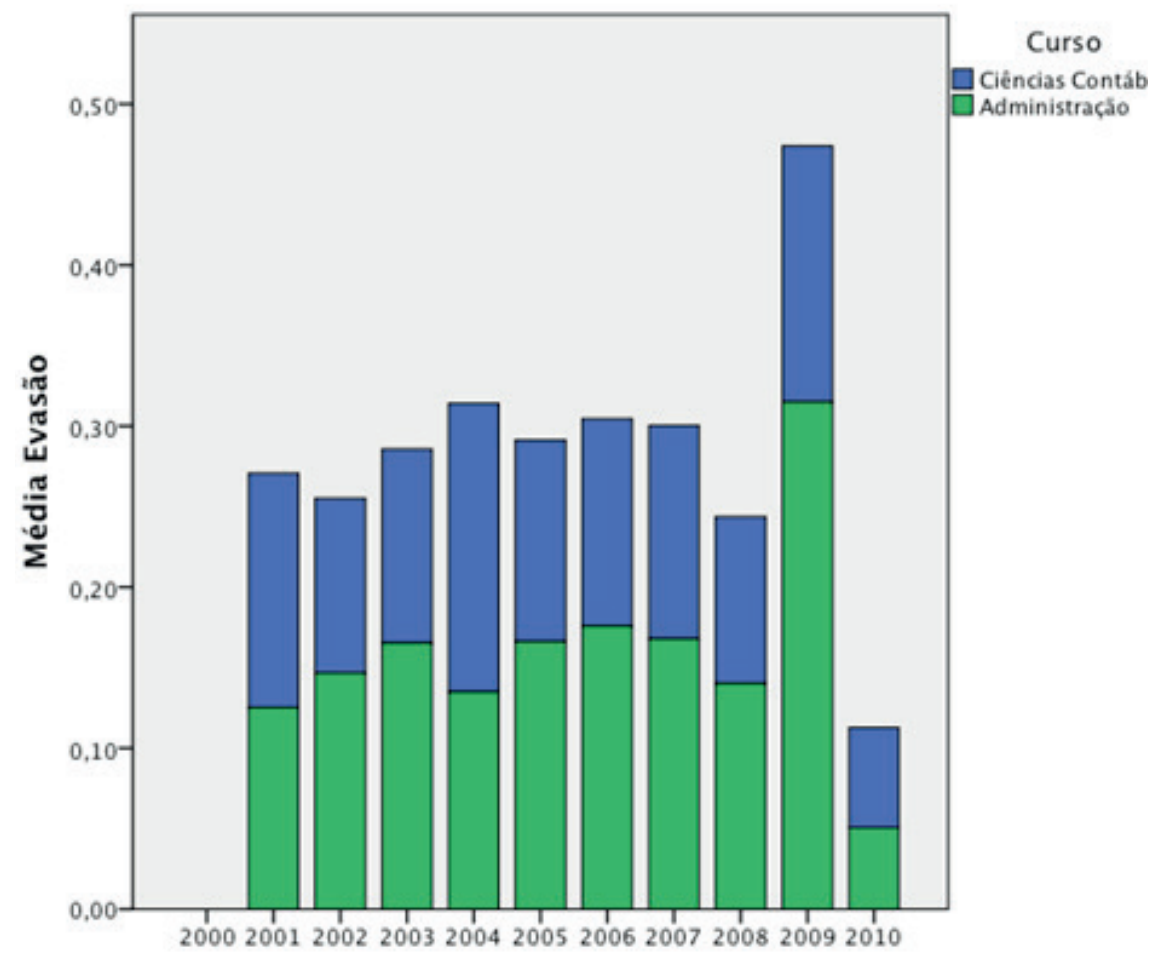

Figura 2. Série temporal das taxas de evasão média de acordo com o curso (Ciências Contábeis vs. Administração de Empresas)

Fonte: os autores.

A taxa de evasão média foi mais alta nos cursos de Administração de Empresas do que nos cursos de Ciências Contábeis durante o período do estudo. A taxa de evasão média mais alta em Administração de Empresas foi observada em 2009. A taxa de evasão média mais alta em Ciências Contábeis ocorreu em 2004.

As taxas de evasão foram organizadas de acordo com as formas de organização acadêmica (ou tipos de instituição acadêmica), conforme consta na Tabela 2.

Tabela 2

Estatística descritiva das taxas de evasão de acordo com a forma de organização acadêmica

\begin{tabular}{lcccc}
\hline Forma de organização acadêmica & Média & Mediana & Desvio padrão & Coeficiente de variação \\
\hline Universidades & $10,38 \%$ & $9,99 \%$ & $2,79 \%$ & $26,87 \%$ \\
\hline Centros Universitários & $11,63 \%$ & $10,40 \%$ & $6,94 \%$ & $59,67 \%$ \\
\hline $\begin{array}{l}\text { Faculdades, escolas, institutos e } \\
\text { centros de ensino tecnológico }\end{array}$ & $20,86 \%$ & $21,44 \%$ & $6,65 \%$ & $31,87 \%$ \\
\hline
\end{tabular}

Fonte: Os autores

As taxas de evasão média e mediana foram mais baixas para o grupo universidades. O coeficiente de variação foi alto em todos os grupos. Os valores medianos e médios sugerem o mesmo padrão dentro de cada tipo de instituição acadêmica. As faculdades, escolas, institutos e centros de ensino tecnológico diferem dos outros dois grupos, mostrando taxas mais próximas daquelas relatadas por Silva et al. (2007) para a área de Ciências Sociais, Negócio e Direito. A Figura 3 mostra a série temporal das taxas de evasão média de acordo com a forma de organização acadêmica, e as diferenças foram analisadas como ANOVA. 


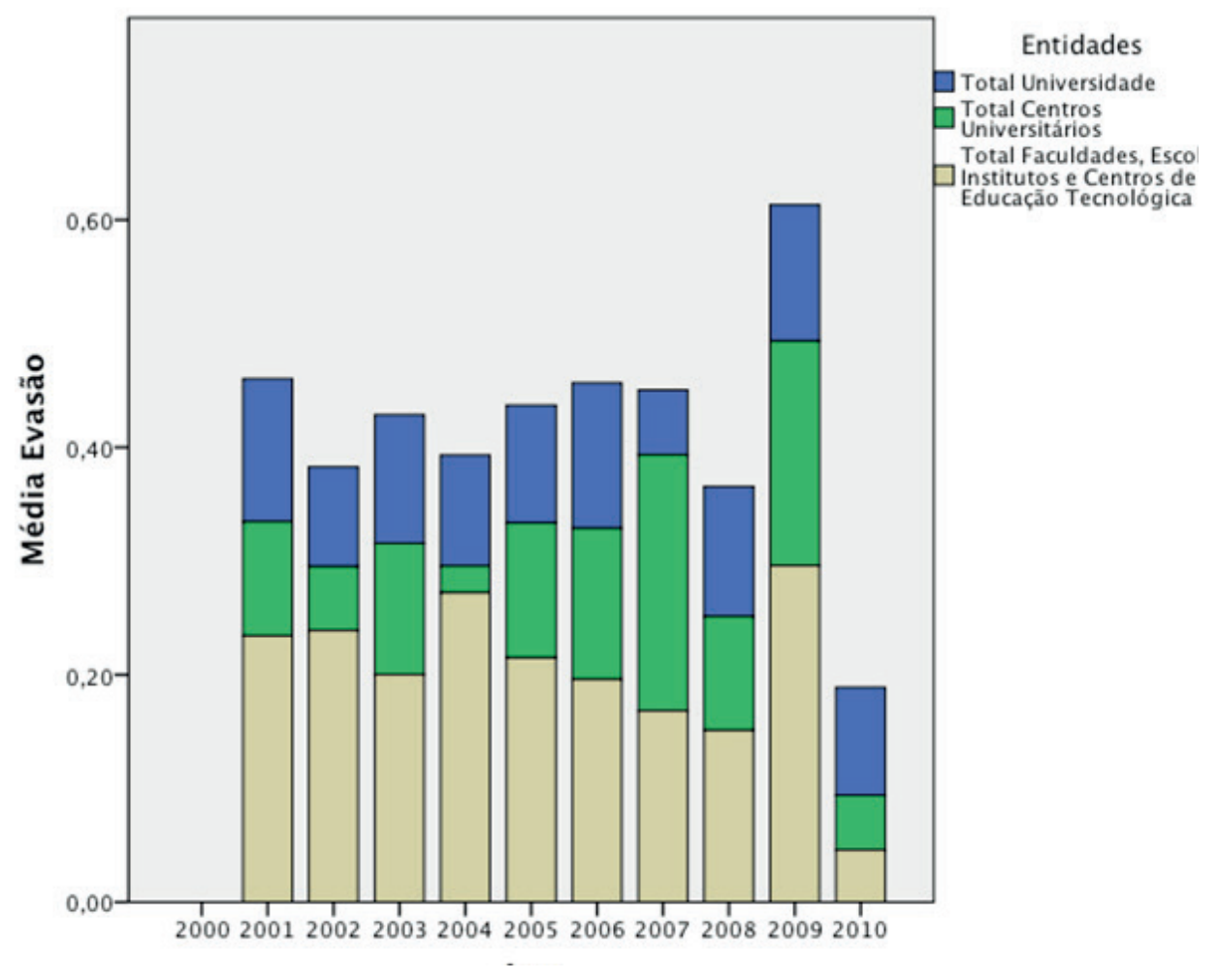

Figura 3. Série temporal das taxas de evasão média de acordo com a forma de organização acadêmica

Fonte: os autores.

A série temporal para o grupo universidades foi quase constante, com a menor taxa de evasão média em 2007. A série temporal dos centros universitários foi menos homogênea, com a menor taxa em 2004. As taxas mais altas foram observadas nas faculdades, escolas, institutos e centros de ensino tecnológico (especialmente em 2009).

As escolas privadas tendem a ter taxas de evasão mais altas do que as instituições públicas, principalmente por causa das dificuldades financeiras. Os programas brasileiros de empréstimo estudantil tais como o Fies (Fundo de Financiamento Estudantil) e o Prouni (Programa Universidade para Todos) podem auxiliar a mudar este cenário. Segundo Wolter et al. (2014), as condições socioeconômicas desfavoráveis são uma causa importante da evasão em muitos países, particularmente no Reino Unido. No Brasil, as universidades públicas são maiores do que as privadas e têm um potencial maior para a retenção dos estudantes.

Após verificar a normalidade e a homocedasticidade dos dados, as amostras foram comparadas por meio do teste ANOVA, resultando em um valor- $p$ de 0,000 , indicando que, pelo menos, um tipo de instituição acadêmica diferia das outras. Finalmente, o teste Tukey a posteriori foi usado para confirmar os resultados das estatísticas descritivas e do ANOVA. O teste revelou que as taxas de evasão médias eram semelhantes para os centros universitários e universidades e que estes dois grupos diferiam significativamente das faculdades, escolas, institutos e centros de ensino tecnológico (Quadro 4). 
Tabela 3

Teste Tukey pareado para igualdade das médias

\begin{tabular}{lllc} 
& \multicolumn{1}{c}{ Totais } & \multicolumn{2}{c}{ Subconjunto para alfa $=\mathbf{0 . 0 5}$} \\
\cline { 2 - 3 } & \multicolumn{1}{c}{ Centros universitários } & \multicolumn{1}{c}{$\mathbf{1}$} \\
\cline { 2 - 3 } Tukey HSDa & Universidades & 0,1164 & $\mathbf{2}$ \\
\cline { 2 - 3 } & $\begin{array}{l}\text { Faculdades, escolas, institutos e centros de ensino } \\
\text { tecnológico }\end{array}$ & 0,1038 & 0,2086 \\
\cline { 2 - 4 } & Sig. & 0,789 & 1,000 \\
\hline
\end{tabular}

Fonte: os autores.

Os resultados do teste evidenciam que as taxas de evasão foram maiores, significativamente, para as faculdades, escolas, institutos e centros de ensino tecnológico do que para os outros tipos de instituições acadêmicas analisados. Em outras palavras, a Hipótese 3 ("existe diferença estatisticamente significativa entre as taxas de evasão nas diferentes formas de organização acadêmica analisadas") não foi rejeitada.

A Tabela 4 mostra como um grande percentual de estudantes concluíram os seus cursos dentro do prazo ideal, expresso como índice do prazo ideal para conclusão do curso (ITCCI). A fórmula usada para calcular o índice está descrita na Seção 3.1.

Tabela 4

Estatísticas descritivas do ITCCI de acordo com o curso

\begin{tabular}{lcccc}
\hline \multicolumn{1}{c}{ Curso } & Média & Mediana & Desvio padrão & Coeficiente de variação \\
\hline $\begin{array}{l}\text { Administração de } \\
\text { Empresas }\end{array}$ & $23,88 \%$ & $19,26 \%$ & $17,19 \%$ & $71,98 \%$ \\
\hline Ciências Contábeis & $22,70 \%$ & $20,94 \%$ & $6,96 \%$ & $30,66 \%$ \\
\hline
\end{tabular}

O ITCCI médio foi ligeiramente mais alto para os cursos de Administração de Empresas (23,88\%) do que para os cursos de Ciências Contábeis (22,70\%), apesar do coeficiente de variação alto (71,98\%). Contudo, ao analisar os valores medianos (não influenciados pelos extremos), o oposto é verdadeiro: o percentual foi mais alto para os cursos de Ciências Contábeis $(20,94 \%)$ do que para os cursos de Administração de Empresas (19,26\%).

Uma comparação entre os índices dos dois cursos, usando o teste Mann-Whitney, gerou um valor- $p$ de 0,178 , indicando que as diferenças entre os cursos eram estatisticamente insignificantes durante o período coberto pelo estudo. Deve ser realçado que as amostras eram homocedáticas, apesar da falta de normalidade na distribuição do ITCCI. Portanto, não se pode dizer que o ITCCI dos dois cursos seja diferente e a Hipótese 2 ("não existe diferença estatisticamente significativa entre o ITCCI dos cursos de Administração de Empresas e Ciências Contábeis”) não foi rejeitada. Em outras palavras, menos de 24\% dos estudantes matriculados nos cursos de graduação em Ciências Contábeise Administração de Empresas concluíram os seus cursos dentro do período estabelecido de cinco anos. Novamente, isso pode ser explicado pelo fato de que a maioria dos estudantes estava empregada durante os seus anos de faculdade.

A Tabela 5 apresenta uma comparação dos valores do ITCCI de acordo com as formas de organização acadêmica. 
Tabela 5

Estatística descritiva do ITCCI de acordo com a forma de organização acadêmica

\begin{tabular}{lcccc}
\hline Forma de organização acadêmica & Média & Mediana & Desvio padrão & Coeficiente de variação \\
\hline Universidades & $18,17 \%$ & $18,13 \%$ & $1,55 \%$ & $8,53 \%$ \\
\hline Centros universitários & $25,13 \%$ & $22,16 \%$ & $8,50 \%$ & $33,82 \%$ \\
\hline $\begin{array}{l}\text { Faculdades, Escolas, Institutos e } \\
\text { Centros de Ensino Tecnológico }\end{array}$ & $26,57 \%$ & $21,37 \%$ & $20,30 \%$ & $38,76 \%$ \\
\hline
\end{tabular}

Fonte: os autores.

Um aumento nos valores médios do ITCCI foi observado do primeiro grupo (universidades) para o segundo (centros universitários) e o terceiro grupo (faculdades, escolas, institutos e centros de ensino tecnológico).

Para determinar se a diferença entre os tipos de instituição acadêmica era significativa, os valores foram submetidos ao teste ANOVA após serem testados para normalidade e homocedasticidade. O teste gerou um valor- $p$ de 0,189 ; deste modo, a Hipótese 4 ("não existe diferença estatisticamente significativa entre o ITCCI nas diferentes formas de instituições acadêmicas analisadas") não foi rejeitada.

Além dos testes de hipóteses, as variáveis foram submetidas à análise de correspondência simples e múltipla, com o intuito de identificar associações entre as variáveis em um mapa. Esse tipo de análise multivariada exige que as variáveis sejam quantitativas. Assim, nenhuma alteração foi exigida para as variáveis "ano", "curso" e "forma de organização acadêmica". Entretanto, a variável "evasão" foi transformada como segue: a) foram calculados quartis da variável evasão; e b) as observações no primeiro quartil foram classificadas como "excelente" (taxa de evasão mais baixa), as observações entre o primeiro e segundo quartil como "boa", as observações entre o segundo e terceiro quartil como "razoável", e as observações entre o terceiro e o quarto quartil como "fraca" ( taxa de evasão mais alta).

Após essa transformação, as variáveis "evasão" e "forma de organização acadêmica" foram submetidas à análise de correspondência simples. $\mathrm{O}$ teste qui- quadrado foi significativo, indicando uma distinção entre as variáveis analisadas. A Figura 4 apresenta uma representação gráfica da associação entre as variáveis.

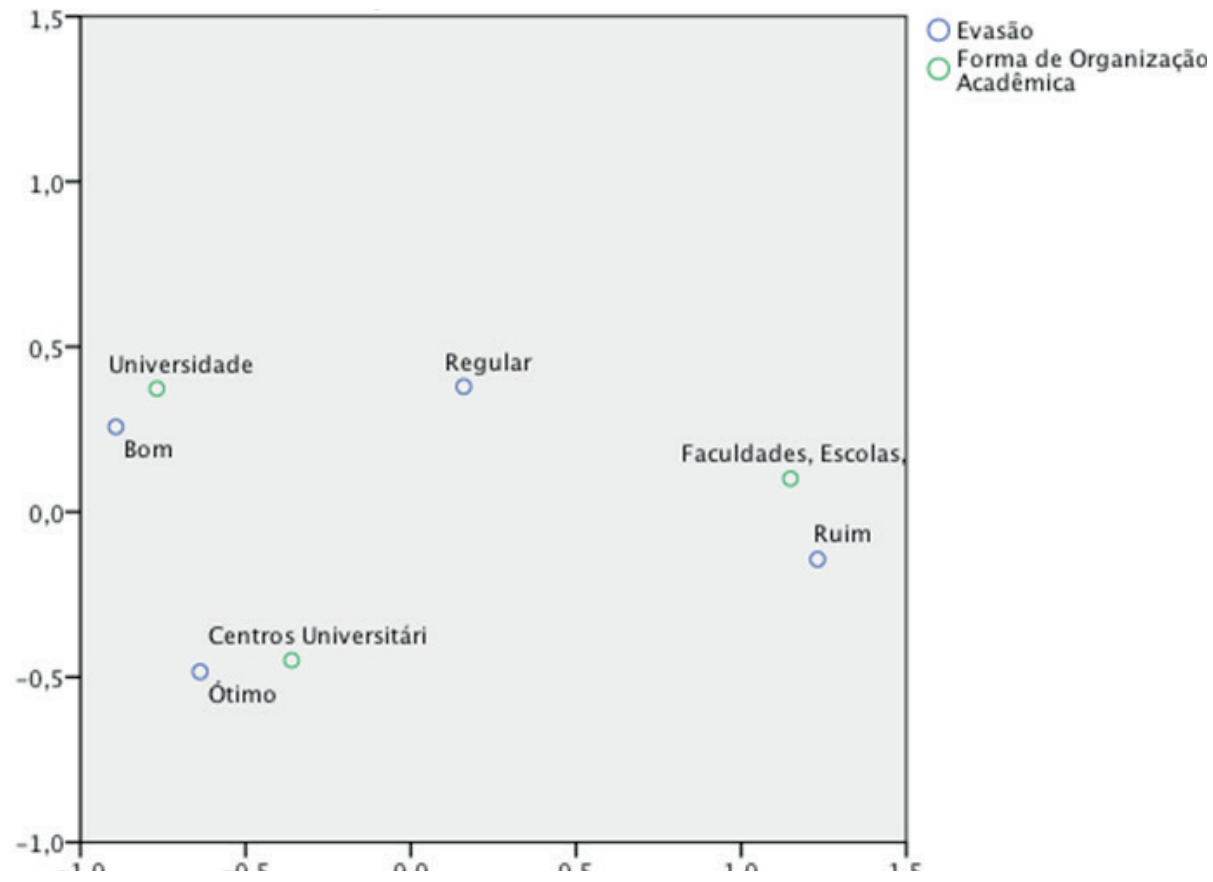

Figura 4. Dispersão das variáveis "evasão" e "forma de organização acadêmica"

Fonte: os autores 
Na Figura 4, embora a observação "razoável" estivesse presente em todos os três tipos de instituição acadêmica, esta não era uma característica proeminente em nenhuma delas. Os centros universitários mostram as taxas de evasão mais baixas, seguidos pelas universidades e faculdades, escolas, institutos e centros de ensino tecnológico.

Quando as variáveis "ano" e "evasão" foram submetidas à análise de correspondência, o resultado do teste qui-quadrado não foi significativo, indicando não haver variação significativa nas taxas de evasão entre os anos.

A variável "curso" teve somente duas especificações (Administração de Empresas e Ciências Contábeis) e não foi, portanto, submetida à análise de correspondência. Este tipo de análise multivariável requer que as variáveis tenham mais de duas especificações. Entretanto, a análise de correspondência múltipla (para a qual não existe tal restrição, exceto a exigência de que as variáveis sejam qualitativas) foi realizada para todas as variáveis.

O Alfa de Cronbach foi 0,526 para todas as variáveis combinadas, o que pode ser considerado baixo e possivelmente é o resultado da ausência de distinção na série temporal (muito estável, poucas mudanças) e pequena distinção entre os cursos.

A Figura 5 apresenta um mapa de dispersão mostrando os resultados da análise de correspondência múltipla das variáveis "ano", "curso", "forma de organização acadêmica" e "evasão".

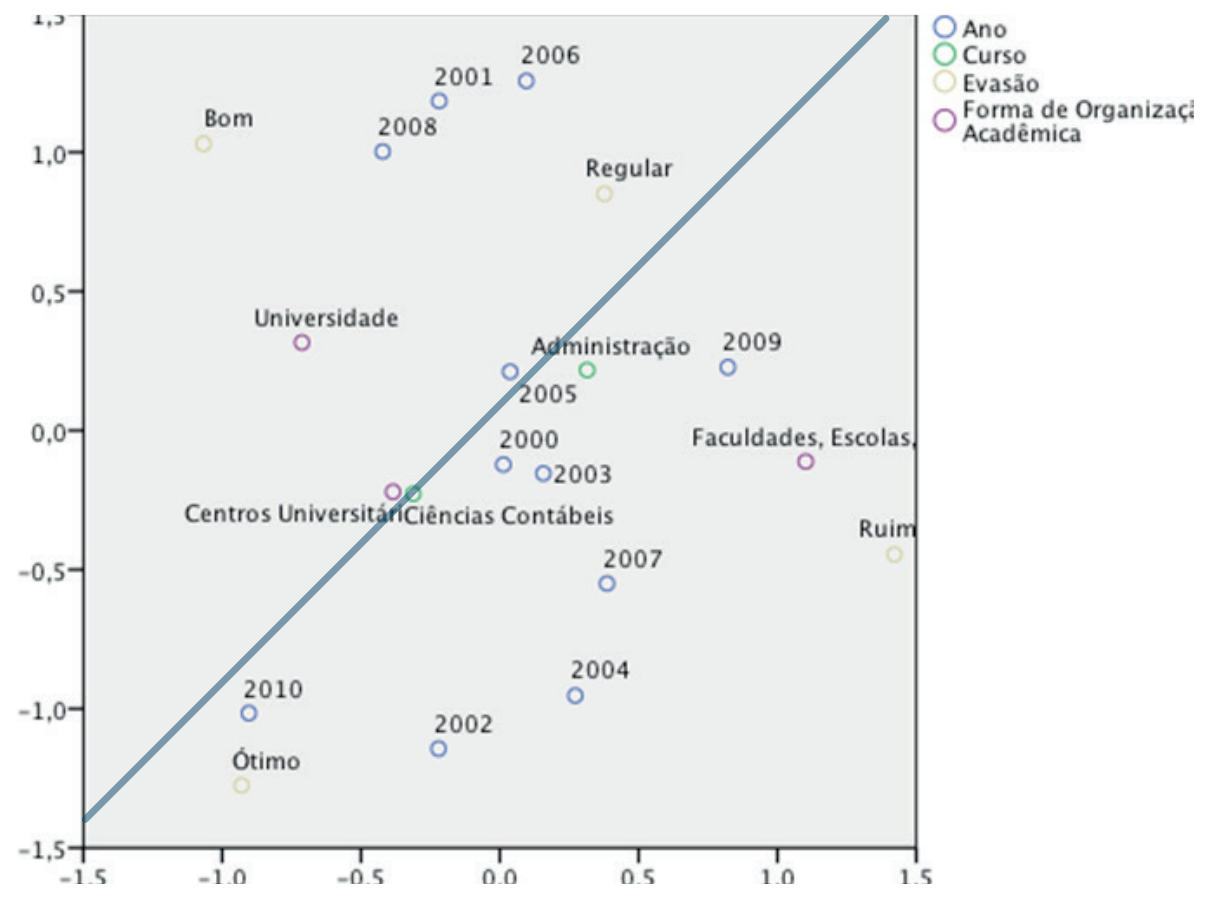

Figura 5. Mapa de dispersão da análise de correspondência multivariada (HOMALS) das variáveis "ano", "curso", "forma de organização acadêmica" e "evasão"

Fonte: os autores.

A linha diagonal na Figura 5 revela taxas de evasão mais baixas para os cursos de Ciências Contábeis, principalmente em 2002, 2003, 2004, 2007 e 2010. Este padrão foi mais evidente para as universidades e centros universitários, em que as taxas de evasão foram mais baixas.

As taxas de evasão foram mais altas para os cursos de Administração de Empresas, principalmente em 2001, 2005, 2006, 2008 e 2009. Este padrão foi mais evidente para as faculdades, escolas, institutos e centros de ensino tecnológico.

Estes resultados não devem ser interpretados como uma generalização, mas representam padrões observados dentro das classificações adotadas no estudo. 


\section{Conclusão}

Nesse estudo analisou-se o comportamento da evasão dos estudantes matriculados em cursos de graduação em Administração de Empresas e Ciências Contábeis nas IES brasileiras entre 2001 e 2010, baseado em dados oficiais publicados pelo Inep em 2012. O propósito principal do estudo foi determinar o perfil da evasão e da conclusão dos cursos. .

A estatística descritiva mostrou níveis de evasão mais altos para os cursos de Administração de Empresas em relação aos cursos de Ciências Contábeis, com níveis gerais mais baixos, se comparados com as conclusões de Silva et al. (2007) para a área de Ciências Sociais, Negócio e Direito, e as conclusões de Noronha et al. (2001) e Correa e Noronha (2004) para os cursos de Administração de Empresas. Os valores medianos revelaram também uma taxa de evasão mais alta para Administração de Empresas do que para Ciências Contábeis. Entretanto, a diferença não foi estatisticamente significativa ao nível de confiança de $95 \%$, confirmando assim a Hipótese 1. Isso pode ser explicado, em parte, pelas similaridades no perfil dos estudantes nos dois cursos, tais como emprego em tempo integral e matricula nos cursos noturnos.

No período coberto pelo estudo, os níveis de evasão foram mais altos em Administração de Empresas do que em Ciências Contábeis, com as taxas mais altas em 2009 (Administração de Empresas) e 2004 (Ciências Contábeis). O teste Tukey revelou que as taxas de evasão médias eram semelhantes para as universidades e centros universitários (neste estudo considerado como dois tipos diferentes de instituição acadêmica), e que estes dois grupos diferiam, significativamente, do grupo representado pelas faculdades, escolas, institutos e centros de ensino tecnológico. A análise estatística mostrou também que as taxas de evasão foram mais altas neste último grupo do que nas universidades e centros universitários (Hipótese 3).

O índice de prazo ideal de conclusão do curso (ITCCI) mediano foi mais alto para Ciências Contábeis, embora não significativamente $(p=0,178)$; assim a Hipótese 2 não foi rejeitada. Os dados mostram que, com relação à Hipótese 4, menos de um quarto dos estudantes concluíram os seus cursos dentro do período esperado de cinco anos, independentemente do tipo de instituição. Pode-se considerar de que devido à conclusão com atraso, adia-se a evasão; as taxas de evasão foram mais baixas nos cursos de $\mathrm{Ci}$ ências Contábeis. Este resultado pode ter sido influenciado pelas similaridades no perfil dos estudantes dos dois cursos (emprego em tempo integral e matrícula nos cursos noturnos).

Além de testar as hipóteses, foi realizada análise de correspondência para verificar as associações possíveis entre as variáveis. Os resultados do teste qui-quadrado foram significativos para as variáveis "forma de organização acadêmica" e "evasão" (indicando distinção), mas não significativos para as variáveis "ano" e "evasão" (nenhuma variação significativa na evasão de ano para ano).

Em geral, as conclusões indicam que os cursos de Ciências Contábeis apresentaram taxas de evasão mais baixas nas universidades e nos centros universitários, enquanto que os cursos de Administração de Empresas apresentaram taxas de evasão mais altas nas faculdades, escolas, institutos e centros de ensino tecnológico. Entretanto, deve ser enfatizado que estes resultados não têm a pretensão de ser uma generalização, mas representam padrões observados dentro das classificações adotadas nesse estudo.

As taxas de evasão alarmantes observadas no estudo e a sua associação com tipos de instituições acadêmicas dão lugar às considerações importantes. Para se reduzir as taxas de evasão atuais, são necessárias políticas capazes de elevar a qualidade do ensino superior no Brasil. Primordialmente, a questão da evasão tem sido tratada de forma transversal, em termos de padrões, enquanto que poucos estudos lidaram com o papel que desempenha a qualidade do ensino oferecido.

Discutiu-se, também, os custos acadêmicos, sociais e econômicos da evasão, independentemente do tipo de instituição acadêmica. Além da frustração pessoal, a evasão está associada com perdas sociais e econômicas significativas. Os agentes envolvidos nesse processo, particularmente os administradores e professores das IES, são aconselhados a desenvolverem estratégias que assegurem o sucesso no estudo (i.e, conclusão do curso dentro do prazo esperado) sem a perda da qualidade do ensino. Esta última é essencial para a aceitação dos formandos no mercado de trabalho. 
Os estudos futuros poderiam explorar o fenômeno da evasão a partir do ponto de vista do financiamento do ensino superior (privado vs. público), ou olhar para as relações entre as taxas de evasão, curso específico e características dos estudantes, tais como cursos noturnos vs. diurnos e o impacto do emprego no comportamento do estudante, ou a influência das tendências educacionais e as demandas da sociedade sobre as escolhas dos estudantes.

\section{Referências}

Astin, A. W. (1984). Student involvement: a developmental theory for higher education. Journal of College Student Personnel, New Jersey, 25(4), pp. 297-308. doi: 10.1177/0972150912466364

Bardagi. M. P. (2007). Evasão e Comportamento Vocacional de Universitários: estudos sobre o desenvolvimento de carreira na graduação. Tese de Doutorado. Programa de Pós-Graduação em Psicologia do Instituto de Psicologia da Universidade Federal do Rio Grande do Sul, Porto Alegre, RS, Brasil.

Bardagi, M. P., Lassance, M. C. P., Paradiso, A. C. \& Menezes, I. A. (2006). Escolha Profissional e Inserção no Mercado de Trabalho: percepções de estudantes formados. Psicologia Escolar e Educacional, 10 (1), pp. 69-82. doi: 10.1590/S1413-85572006000100007

Bean, J. P. (1980). Dropout and turnover: The synthesis and test of a causal model of student dropout. Research in Higher Education, New York, 12, pp.155-187. doi: 10.1007/BF00976194

Biazus, C. A. (2004). Sistema de fatores que influenciam o aluno a evadir-se dos cursos de graduação na UFSM e na UFSC: um estudo no curso de Ciências Contábeis. Tese de Doutorado. Programa de Pós-Graduação em Engenharia de Produção da Universidade Federal de Santa Catarina, Florianópolis, SC, Brasil.

Brasil. Ministério da Educação. Secretaria da Educação Superior - SESu. (1996). Diplomação, retenção e evasão nos cursos de graduação em instituições de ensino superior públicas. Relatório da Comissão Especial de Estudos sobre Evasão nas Universidades Públicas Brasileiras. Brasília: SESu-MEC.

Brasil. Ministério da Educação. Secretaria da Educação Superior - SESu. (2003). O ensino superior no mundo e no Brasil: condicionantes, tendências e cenários para o horizonte 2003-2005. Retrieved in August 14, 2011 from <http://portal.mec.gov.br/sesu/arquivos/pdf/ensinosuperiormundobrasil tendenciascenarios2003-2025.pdf $>$.

Brasil. Ministério da Educação. Instituto Nacional de Educação e Pesquisa. Inep. (2005). Retrieved in August 12, 2011 from http://www.inep.gov.br/download/enade/2005/resumotecnicoanexoivrespostaquestionariosocioeconomico.pdf:

Cabrera, A. F., Castañeda, M. B., Nora, A. \& Hengstler, D. (1992). The convergence between two theories of college persistence. Journal of Higher Education, Columbus, 63(2), pp. 143-164. doi: 10.2307/1982157

Carmo, M. C. do C. \& Polydoro, S. A. J. (2010, julho/dezembro). Integração ao Ensino Superior em um curso de Pedagogia. Revista Semestral da Associação Brasileira de Psicologia Escolar e Educacional, São Paulo. 14(2), pp. 221-231. doi: 10.1590/S1413-85572010000100005

Chapman, D. W. \& Pascarella, E. T. (2005). Predictors of academic and social integration of college students. Research in Higher Education, New York. 19(3), pp. 295-322. doi: 10.1007/BF00992627

Cislaghi, R. (2008). Um Modelo de Sistema de Gestão do Conhecimento em um Framework para a Promoção da Permanência Discente no Ensino de Graduação. Tese de Doutorado. Programa de Pós-Graduação em Engenharia e Gestão do Conhecimento da Universidade Federal de Santa Catarina, Florianópolis, SC, Brasil. doi : 10.1590/S1414-40772014000100005 
Corrêa, A. C. C. \& Noronha, A. B. (2004). Avaliação da evasão e permanência prolongada em um curso de graduação em administração de uma universidade pública. Anais do Semead - Seminários de Administração, São Paulo, SP, Brasil, 7.

Cunha, J. V. A. (2007). Doutores em Ciências Contábeis da FEA/USP: análise sob a óptica da teoria do capital humano. Tese de Doutorado. Faculdade de Economia e Contabilidade da Universidade de São Paulo. São Paulo: FEA/USP. São Paulo, SP, Brasil.

Fernandes, R. \& Menezes-Filho, N. A. (2000). A evolução da desigualdade de rendimentos no Brasil metropolitano entre 1983 e 1987. Estudos Econômicos, 30(4) , pp. 549-569.

Fernandes, R. \& Narita, R. (2001). Instrução superior e mercado de trabalho. Economia Aplicada, 5(1). DOI: http://dx.doi.org/10.1590/S1413-80502007000400002

Gaioso, N. P. L. (2005). O fenômeno da evasão escolar na educação superior no Brasil. Dissertação de Mestrado. Programa de Pós-Graduação em Educação da Universidade Católica de Brasília, Brasília, DF.

Gall, M. D., Gall, J. P. \& Borg, W. R. (2003). Educational research: an introduction (7nd ed.). Boston: Allyn and Bacon, 49, pp.467-493. doi:10.1177/0013164485454021

Heublein, U. (2014). Student Drop-out from German Higher Education Institutions. European Journal of Education, 49(4). doi:10.1111/ejed.12097

Hotza, M. A. S. (2000). O abandono nos cursos de graduação da UFSC em 1997: a percepção dos alunos-abandono. Dissertação de Mestrado. Programa de Pós-Graduação em Psicologia, UFSC, Florianópolis, SC, Brasil.

Langoni, C. (1973). Distribuição de renda e desenvolvimento no Brasil. Rio de Janeiro: Expressão e Cultura.

Leon, F. F. L. \& Menezes-Filho, N. A. (2002). Reprovação, avanço e evasão escolar no Brasil. Pesquisa e Planejamento Econômico, 32(3), pp. 417-452.

Lins, M. L. \& Silva, R. V. (2005). Estudo da evasão acadêmica - 1970 - 2005. Relatório Técnico. Florianópolis: Departamento de Engenharia Mecânica da UFSC, Florianópolis, SC, Brasil.

Martins, G. A. \& Theóphilo, C. R. (2009). Metodologia da investigação científica para ciências sociais aplicadas (2nd ed.). São Paulo: Atlas.

Menezes-Filho, N. A. (2001). Educação e desigualdade. In: Lisboa, M., \& Menezes-Filho, N. A. (orgs.), Microeconomia e sociedade no Brasil (pp. 13-49 ). Rio de Janeiro: EPGE.

Mercuri, E. N. G. da S., Ajub, J. C. \& Bariani, I. C. D. (1998). Dificuldades encontradas por universitários ingressantes. Anais do Congresso de Psicologia Escolar , João Pessoa, PB, Brasil, 4.

Moraes, J. O. \& Theóphilo, C. R. (2010). Evasão no ensino superior: estudo dos fatores causadores da evasão no Curso de Ciências Contábeis da Universidade Estadual de Montes Claros - Unimontes. Anais do Congresso USP de Controladoria e Contabilidade, São Paulo, SP, Brasil, 10.

Nassar, S. M., Ohira, M., Cislaghi, R. \& Rodrigues, R. S. (2008). Do Modelo Presencial para o Modelo a Distância: variáveis endógenas e os riscos de evasão nos cursos de graduação. Anais do Congresso Brasileiro de Ensino Superior a Distância, Gramado, RS, Brasil, 5.

Noronha, B. N., Carvalho, B. M. \& Santos, F. F. F. (2001). Perfil dos alunos evadidos da Faculdade de Economia, Administração e Contabilidade campus Ribeirão Preto e avaliação do tempo de titulação dos alunos atualmente matriculados. Documento de Trabalho. NUPES - Núcleo de Pesquisa sobre Ensino Superior, Universidade de São Paulo, São Paulo, SP, Brasil.

Palharini, F. A. (2008). Contornos da evasão no curso de letras da UFF. Cadernos de Letras da UFF 36(1), pp. 145-164. 
Pascarella, E.T., Duby, P.B. \& Iverson, B.K. (1983). A text and reconceptualization of a theoretical model of college withdrawal in a Commuter Institution Setting. Sociology of Education, Albany, 56 (2), pp. 88-100. doi:10.2307/2112657

Pereira, E. R. (2004). Acompanhamento da trajetória escolar dos alunos da Universidade de São Paulo: ingressantes de 1995 a 1998. São Paulo: Pró-Reitoria de Graduação da USP. Retrieved in August 14, 2011 from <http://naeg.prg.usp.br/siteprg/ uploads/20041109185134.pdf>.

Pereira, F. C. B. (2003). Determinantes da evasão de alunos e os custos ocultos para as instituiçães de ensino superior: uma aplicação na Universidade do Extremo Sul Catarinense. Tese de Doutorado.Centro Tecnológico, Universidade Federal de Santa Catarina, Florianópolis, SC, Brasil.

Platt Neto, O. A., Cruz, F. \& Pfitscher, E. D. (2008). Utilização de metas de desempenho ligadas à taxa de evasão escolar nas universidades públicas. Repec Revista de Educação e Pesquisa em Contabilidade, 2(2), pp. 54-74.

Polydoro, S. A. J. (2000). O trancamento de matrícula na trajetória acadêmica do universitário: condições de saída e de retorno à instituição. Tese de Doutorado. Universidade Estadual de Campinas, Campinas, SP, Brasil. doi:10.1590/S1413-85572001000100014

Reis, J. \& Barros, R. (1991). Wage inequality and the distribution of education. Journal of Development Economics, 36(1), pp. 117-143.

Ribeiro, S. C. (1991). A pedagogia da repetência. Estudos avançados, São Paulo, 5, 12. Retrieved in March 9, 2012 from <http://www.scielo.br/scielo.php?script=sci_arttext\& pid=S0103$-40141991000200002 \& \operatorname{lng}=$ en\&nrm=iso $>$. doi: 10.1590/S0103-40141991000200002

Rozenstraten, A. S. (1992). Abordagem Psicossocial da Escolha Profissional. VI Encontro Paranaense de Psicologia, Curitiba, PR, Brasil.

Sampieri, R. H., Collado, C. F. \& Lucio, P. B. (2006). Metodologia de pesquisa (3nd ed.). São Paulo: McGraw-Hill.

Santos, F. F. F. \& Noronha, A. B. (2001). Estudo do perfil dos alunos evadidos da Faculdade de Economia, administração e Contabilidade - Campus Ribeirão Preto. Anais do Semead - Seminários de Administração, São Paulo, SP, Brasil, 5.

Silva Filho, R. L. L., Motejunas, P. R., Hipólito, O. \& Lobo, M. B. C. M. (2007). A evasão no ensino superior brasileiro. Cadernos de Pesquisa, São Paulo, 37(132), pp. 641-659. Retrieved in August 14, 2011 from $<$ http://www.scielo.br/pdf/cp/v37n132/a0737132.pdf >. doi:10.1590/S0100-15742007000300007

Soares, D. H. P. (2002). A Escolha Profissional: do jovem ao adulto. São Paulo: Summus.

Souza, I. (1999). Causas da evasão nos cursos de graduação da UFSC. Dissertação de Mestrado. Centro Sócio-Econômico, Universidade Federal de Santa Catarina, Florianópolis, SC, Brasil.

Teixeira, M. A. P. (2002). A Experiência de Transição entre a Universidade e o Mercado de trabalho na Adultez Jovem. Tese de Doutorado. Programa de Pós-Graduação em Psicologia do Instituto de Psicologia da Universidade Federal do Rio Grande do Sul. Porto Alegre, RS, Brasil.

Troelsen, R. \& Laursen, P. F. (2014). Is Drop-out from University Dependent on National Culture and Policy? The Case of Denmark. European Journal of Education, 49(4) DOI: 10.1111/ejed.12094

Tinto, V. (1975). Dropout from higher education: a theoretical synthesis of recent research. Review of Educational Research, Washington, 45(1), pp. 89-125. doi:10.3102/00346543045001089

Veloso, T. C. M. A. \& Almeida, E. P. (2002, janeiro/junho). Evasão nos cursos de graduação da Universidade Federal de Mato Grosso, campus universitário de Cuiabá: um processo de exclusão. Série Estudos, Campo Grande, 13, pp. 133-148. 
Yepes, F.L., Beltrán, M., Arrubla, J., Marín, L.M., Martínez, M., Tobón, C. \& Hoyos, A. M. (2007). Factores causales de la deserción estudiantil en el pregrado de la Facultad de Odontología de la Universidad de Antioquia de 1997 a 2004. Revista Facultad Odontología Universidad de Antioquia, 19 (1), pp. 35-48.

Wolter, S. C., Diem, A. \& Messer, D. (2014). Drop-outs from Swiss Universities: an empirical analysis of data on all students between 1975 and 2008. European Journal of Education, 49(4) DOI: 10.1111/ ejed.12096 